\title{
Effect of Salts on the Tunability of Photonic Gels
}

\author{
Youngjong Kang \\ Department of Chemistry, Hanyang University, Seoul 133-791, Korea. E-mail: youngjkang@hanyang.ac.k. \\ Received October 8,2008
}

Key Words : Photonic gel, Tunable, Salt, IIofmeister series, Kosmotrope

Photonic band gap (PBG) materials with tunability in the visible or near infrared region have been increasingly investigated not only because of their unique capability of controlling and processing light but also because of their potential applications as an active component of display, sensory or telecommunication devices. ${ }^{1-5}$ Collective Bragg refraction in a periodic dielectric structure delivers a certain range of frequency called photonic band gap where the propagation of photon is prohibited. ${ }^{6}$ The band structures can be modulated when the refractive index and the periodicity of the dielectric layers are carefully scaled to the wavelength of incident light. Many different tunable PBG materials have been demonstrated, and most of them are based on the colloidal crystal arrays (CCAs) functionalized with various molecules where either the refractive index or the periodicity is responsively changed to the various stimuli. $^{7-9}$ Block copolymers also have been proposed as platforms of creating various PBG structures. For instance, it was demonstrated that self-assembly of block copolymers can provide an effective way of fabricating $1 \mathrm{D}, 2 \mathrm{D}$ and $3 \mathrm{D}$ PBG materials from lamellae, hexagonally packed cylinders and double gyroids respectively. ${ }^{10-12}$ In this case, the band structures could be further modulated by changing domain spacing and refractive index contrast. Our group recently reported chemically tunable photonic gels which were spontaneously assembled from block copolymers. ${ }^{13}$ Our general strategy was based on the selective swelling of block copolymer lamellae consisting of altemating non-swellable glassy layers and highly charged gel layers which can be swollen by aqueous solvents. As the gel layers are swollen by aqueous solvents having low refractive index, both the domain spacing and the refractive index contrast between the layers increase, and which results in the shift of the photonic band position to longer wavelengths. Since they consist of highly charged hydrogels, photonic gels were very responsive to the change of ionic strength of solution.

Herein we investigated the effect of salt on the turnability of PBG of block copolymer photonic gels. Photonic gels were prepared by the previously reported method. ${ }^{13}$ Briefly, PS- $b$-P2VP lamellar films were first prepared by spin casting from PS- $b$-P2VP $\left(\mathrm{M}_{\mathrm{n}} \times 10^{3}=190 / 190\right.$ or 57/57) solution in propylene glycol monomethyl ether acetate (PGMEA), and subsequently annealed with chloroform vapor at $50^{\circ} \mathrm{C}$ for 24 hours. Gel layers (QP2VP) were then formed by quatemizing the $\mathrm{P} 2 \mathrm{VP}$ layers in the mixture of jodomethane and hexane at $50^{\circ} \mathrm{C}$ for 24 hours. The originally unswellable lamellar films became swellable with aque- ous solvents, when pyridine groups were converted to pyridinium by reacting with jodomethane. The quatemized photonic gel films were, then, immersed into $0.1 \mathrm{M}$ ammonium chloride solution for 4 hours to replace iodide ions with chloride jons. After washing with copious DI water, the photonic gel films were dried and saved for further experiments.

Since the domain spacing of dried photonic gel films is not sufficiently large to show a PBG in the visible wavelengths, they were transparent without showing any color. However, the films immediately exhibited clearly visible color with strong reflection as they were immersed in water, and persistently showed the color as long as they were in water. The color of the photonic gel films swollen in water can be further modulated by changing the ionic strength of solution. Similar to many polyelectrolyte gels, the photonic gels collapse when placed in aqueous salt solution. ${ }^{1+15}$ The changes of PBG were characterized by UV-VIS. Since the absorbance maximum directly represents the $P B G$, the optical properties of the photonic gels can be easily monitored by taking UV-VIS absorbance with change of salt concentration. As shown in Figure 1, the PBG position logarithmically shifted to the shorter wavelength as increasing salt concentration. This implies that QP2VP gel layers more collapsed at higher salt concentration. Because of logarithmical behavior, the tunability of $\mathrm{PBG}$ was much high at lower salt concentration. The tunability of PBG against salt concentration was also highly dependent on the molecular weight of PS- $b$-P2VP. The photonic gels prepared with higher molecular weight PS- $b$-P2VP $\left(\mathrm{M}_{\mathrm{n}} \times 10^{3}=190 / 190\right)$

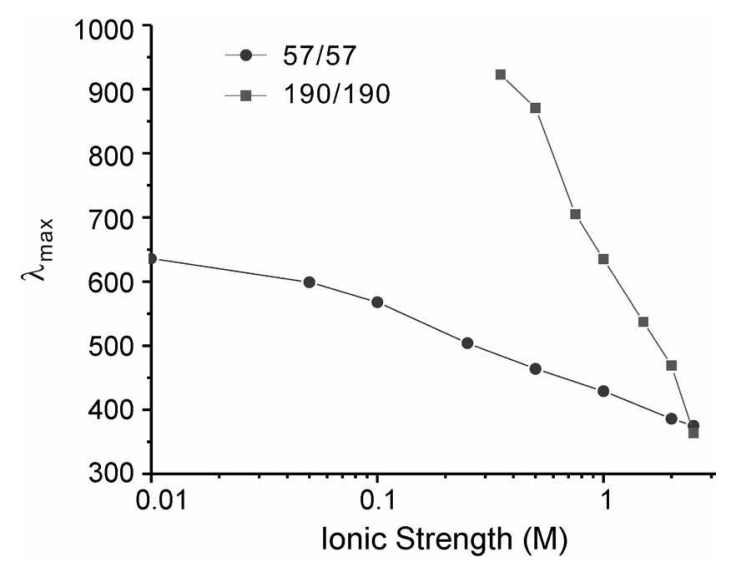

Figure 1. The change of $\mathrm{PBG}$ position of photonc gels with increase of ionic strength. The molecular weights of PS-b-QP2VP were (i) $\mathrm{M}_{12} \times 10^{3}=57 / 57$ (ii) $\mathrm{M}_{12} \times 10^{3}=190 / 190$. 


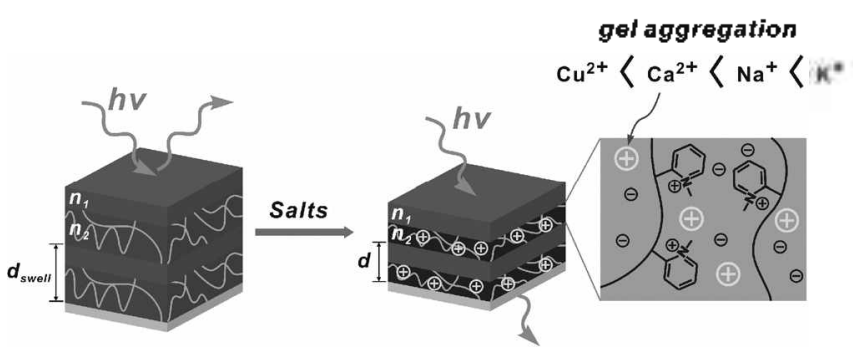

Scheme 1

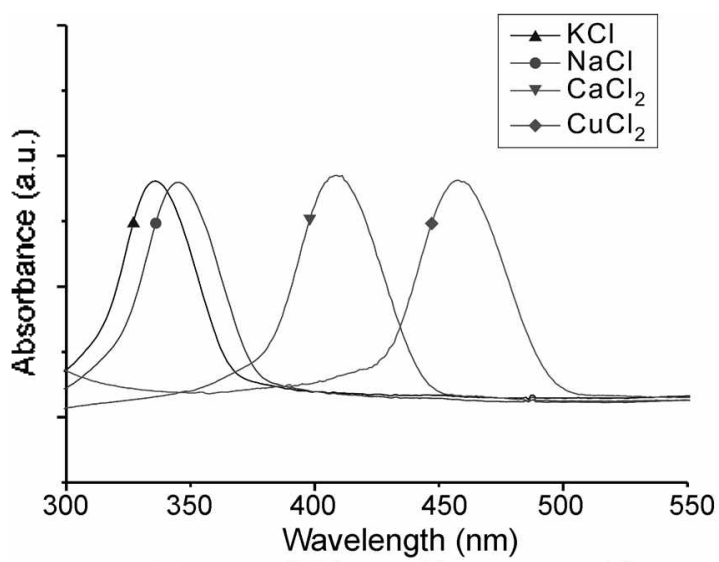

Figure 2. The effect of the size of cation on the position of $\mathrm{PBG}$ The ionic strength of solution was fixed at $2 \mathrm{M}$ for all salts.

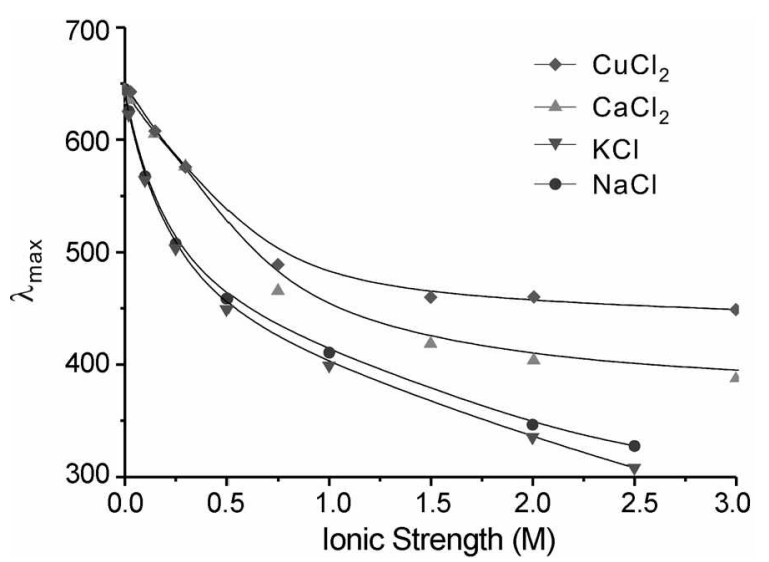

Figure 3. The effect of the size of cation on the position of PBG

response more sensitively to the salt concentration than low molecular weight one $\left(\mathrm{M}_{\mathrm{n}} \times 10^{3}=57 / 57\right)$.

We have investigated the effect of salt cation on the optical properties of the photonic gels (Figure 2, 3). Figure 2 shows UV-VIS spectra of the photonic gels which were swollen with several different kinds of salt solutions at the same ionic strength $(2 \mathrm{M})$. Only to compare the effect of cation, anion was fixed with $\mathrm{Cl}^{-}$. In this case, since $\mathrm{Cl}^{-}$is also same as the counter-anion of QP2VP, there is no side effect by ion exchange. In this set of experiments, we found that the PBG position is highly dependent on the size of cations. Our results show that the larger cations induce the shift of $\mathrm{PBG}$ to the shorter wavelength: the jonic radij of cations are $\mathrm{K}^{+}$ $(1.38 \AA), \mathrm{Na}^{+}(1.02 \AA), \mathrm{Ca}^{2+}(1.00 \AA)$ and $\mathrm{Cu}^{2+}(0.73 \AA)$ (Scheme 1). ${ }^{16}$ The shift of PBG to the shorter wavelength represents collapse of the QP2VP gel layers. This trend was consistent within our experimental range of ionic strength $(0-3 \mathrm{M})$. The PBG difference between the samples increased as increasing ionic strength (Figure 3). This cation size dependent optical property of photonic gels can be explained with Hofmeister series. ${ }^{17}$ It is known that larger cations induce more efficiently ordering of water molecules which increase the surface tension of water. Salts with these properties are called kosmotropes; they are effective at aggregating polyelectrolyte gels. ${ }^{18.19}$ Our results are consistent with the order of Hofmeister series.

In summary, we have investigated the effect of salt on the optical properties of photonic gels. Our results show that PBG shift logarithmically to the shorter wavelength as increasing salt concentration, and this was more prominent for photonic gels prepared with higher molecular weight polymer. Added cations behaved as ksmopropes following Hofmeister series. In general, larger cations induce large shift of PBG to the shorter wavelength by inducing the collapse of QP2VP layers.

Acknowledgments. This work was supported by the Research fund of HYU (HYU-2008-T).

\section{References}

I. Joannopoulos, J. D.; Meade, R. D.; Winn, J. N. Photonic Crystals: Molding the Flow of Light; Princeton University Press: Princeton, 1995.

2. Alexeev, V. L.; Das, S.; Finegold, D. N.; Asher, S. A. Clin. Chen. 2004, 50, 2353.

3. Asher, S. A.; Alexeev, V. L.; Goponenko, A. V.; Sharma, A. C.; Lednev, I. K.; Wilcox, C. S.; Finegold, D. N. J. Am. Chem. Soc. $2003,125,3322$.

4. Xu, X. L.; Friedman, G; Humfeld, K. D.; Majetich, S. A.; Asher, S. A. Adv. Mater 2001, 13,1681.

5. Arsenault, A. C.; Clark, T. J.; von Freymann, G.; Cademartiri. L.; Sapienza, R.; Bertolotit, J.; Vekris, E.; Wong, S.; Kitaev, V; Manners, I.; Wang, R. Z.; John, S.; Wiersma, D.; Ozin, G. A. Nat. Mater, 2006, $5,179$.

6. Joannopoulos, J. D.; Villeneuve, P. R.; Fan, S. Nattire 1997, 386, 143.

7. Weissman, J. M.; Sunkara, H. B.; Tse, A. S.; Asher, S. A. Science $1996,274,959$.

8. Gu, Z.-Z,; Fujishima, A.; Sato, O. J. Am. Chem. Soc. 2000, 122, 12387.

9. Foulger, S. H.; Jiang, P.; Ying. Y.; Lattam, A. C.; Smith, D. W., Jr.; Ballato, J. Adv Mater. 2001, 13, 1898.

10. Urbas, A.; Sharp, R.; Fink, Y.; Thomas, E. L.; Xenidou, M.; Fetlers, L. J. Adr. Mater: $2000,12,812$.

11. Deng, T.; Chen, C.; Honeker, C.; Thomas, E. L. Polymer 2003, 44,6549 .

12. Urbas, A. M.; Maldovan, M.; DeRege, P.; Thomas, E. L. $A d v$. Mater 2002, $14,1850$.

13. Kang, Y.; Walish, J. J.; Gorishnyy, T.; Thomas, E. L. Nat. Mater. $2007,6,957$.

14. Starodoubtsev, S. G; Khokhlov, A. R.; Sokolov, E. L.; Chu, B. Macromolecules 1995, 28, 3930 .

15. Ohmine, J.; Tanaka, T. J. Chem. Phys. 1982, 77, 5725.

16. Shannon, R. D. Acta Cnytallogr. Sect. A 1976, A32, 751.

17. Hofineister, F. Arch. Exp. Pathol. Pharnakol. 1888, $24,247$.

18. Cacace, M. G.; Landau, E. M.; Ramsden, J. J. Q. Rev Biophys. 1997, 30, 241 .

19. Collins, K. D. Proc. Natl. Acad. Sci. 1995, 92, 5553. 